\title{
O VALOR SOCIOECONÓMICO DA ENFERMAGEM NO CONTEXTO DE PANDEMIA PELA COVID-19: CENÁRIO EM PORTUGAL
}

Esperança do Gago Alves Pereira. Pós-Doutorado em Enfermagem; Doutorada em Ciências da Educação; Mestre em Enfermagem e Especialista em Enfermagem de Reabilitação. Universidade do Minho - Escola Superior de Enfermagem - Braga- Portugal. E-mail: epereira@ese.uminho.pt

A Enfermagem é uma profissão com cerca de vinte e três milhões de enfermeiros a nível mundial e é consensual internacionalmente, que é a espinha dorsal do sistema de saúde de qualquer país. Este grupo profissional é determinante para que os sistemas de saúde mundiais consigam responder às profundas alterações demográficas e maior prevalência de doenças crónicas ao longo da vida. Estes e outros fatos contribuíram para que o ano 2020 fosse nomeado como o Ano Internacional do Enfermeiro e da Parteira ${ }^{(1)}$.

No entanto o ano de 2020, não ficou marcado com comemorações como seria desejável a partir do momento em que a Organização Mundial de Saúde (OMS) ${ }^{(2)}$ através de declarações do seu diretor Geral, em 11 de março de 2020, elevou o estado da contaminação da pandemia de Covid-19, doença causada pelo novo coronavírus (Sars-Cov-2). O ano de 2020 está sim, a ser marcado por desafios, contingências e exigência de perícia colocados aos serviços de saúde, profissionais de saúde e especialmente aos enfermeiros, como já referido a espinha dorsal do sistema de saúde.

Os enfermeiros estão e estarão sempre na linha de frente. Também em Portugal estes suportam e apoiam as Orientações da Direção Geral da Saúde (autoridade de saúde do governo português, que funciona como um serviço do Ministério da Saúde). Na primeira fase de mitigação com medidas transversais de preparação, assim como outras orientações que se seguiram de acordo com a evolução das fases e propagação desta pandemia, salvaguardaram a manutenção da saúde pública buscando garantir a prestação desses cuidados por uma questão de equidade, de responsabilidade e acessibilidade ${ }^{(3)}$.

Os enfermeiros portugueses têm atuado com elevado desempenho no âmbito de um cuidado integral de enfermagem nas áreas criadas e denominadas como áreas dedicadas para avaliação e tratamento de doentes COVID-19 (ADC). As ADC correspondem a locais/infraestruturas bem identificadas, com sinalética apropriada, para garantir a separação dos circuitos dos doentes com suspeita ou infeção por SARS-CoV-2 face aos restantes.

Em Portugal, através da reestruturação dos serviços de saúde com a gestão de recursos materiais, recursos humanos e de espaços, foram criadas as seguintes áreas dedicadas para a avaliação e tratamento de doentes com a COVID-19 (ADC). Nos serviços hospitalares foi montada uma ADC em cada Serviço de Urgência e enfermarias dedicadas ao tratamento de doentes com a COVID-19. Foi feita uma reorganização 
dos Serviços e Unidades de Medicina Intensiva para garantir a separação de doentes com COVID-19 foram criadas áreas, fora dos Serviços de Medicina Intensiva como forma de prestar os primeiros cuidados aos doentes críticos, de acordo com a sua gravidade e áreas dedicadas à prestação de cuidados em fim de vida. Nos Cuidados de Saúde Primários foi instalada pelo menos uma ADC em cada Agrupamento de Centros de Saúde (ADC-Comunidade) conforme a densidade populacional, a dispersão geográfica e a evolução epidemiológica regional e local de COVID-19(4)

A síntese feita sobre o trabalho, empenho e envolvimento dos enfermeiros portugueses, que poderiam ser outros com qualquer outra nacionalidade, na resposta ao impacto que a pandemia provocou e poderá ainda continuar a provocar pela doença COVID-19, enaltece a nossa convicção da importância e da imprescindibilidade dos enfermeiros a nível mundial pelo seu valor socioeconómico e da crescente consciencialização de que o investimento em enfermagem traz retornos elevados para a sociedade.

O relatório Triple Impact (APPG,2016) produzido pelo Grupo Parlamentar Multipartidário sobre Saúde Global - All-Party Parliamentary Group on Global Health, clarifica de que a cobertura universal de saúde não pode ser alcançada sem o fortalecimento da enfermagem globalmente. Em parte, trata-se de aumentar o número de enfermeiros, mas também de garantir que sua contribuição seja devidamente compreendida e de permitir que trabalhem promovendo todo o seu potencial. Para tal, os enfermeiros deveriam ter voz e serem nomeados pelo poder político para cargos de decisão e consultadoria sobre políticas de saúde ${ }^{(5)}$.

Em investigação teremos que apostar em estudos sobre o impacto económico da enfermagem e utilizar cada vez mais a evidência já existente e explorar sua utilização através da translação do conhecimento, com vista a aumentar os benefícios da inovação e experiência global e regional para o reforço dos sistemas de saúde e a melhoria da saúde das pessoas ${ }^{(6)}$.

Que a nomeação do ano 2020 como o Ano Internacional do Enfermeiro e da Parteira e os desafios que 2020 nos trouxe, através da pandemia da COVID-19, sejam a provocação necessária para o desenvolvimento de novos paradigmas da enfermagem, através de conquistas obtidas pelos enfermeiros por lugares políticos e de liderança onde possam dar expressão e expansão à promoção da saúde e ao bem-estar das pessoas e das comunidades onde estas se inserem, evidenciando o valor socioeconómico da enfermagem.

\section{REFERÊNCIAS}

1. World Health Organization (WHO). Year of the Nurse and the Midwife [Internet]. Washington: WHO; 2020 [cited 2020 July 20]. Available from: https://www.who.int/campaigns/year-of-the-nurse-and-themidwife-2020.

2. World Health Organization (WHO). Coronavirus disease (COVID-19) pandemic [Internet]. Washington: WHO; 2019 [cited 2020 Mar 15]. Available from: https://www.who.int/emergencies/diseases/novelcoronavirus-2019 
3. Freitas MGG. Norma no 004/2020 de 23/03/2020 atualizada a 14/10/2020: COVID-19: Abordagem do doente com suspeita ou confirmação de COVID-19. Portugal: Serviço Nacional de Saúde; 2020a.

4. Freitas MGG. Norma no 007/2020: Prevenção e controlo de infeção por SARS-CoV-2 (COVID-19): Equipamentos de Proteção Individual (EPI). Portugal: Serviço Nacional de Saúde; 2020b.

5. All-Party- Parliamentary Group on Global Health. Triple Impact: How developing nursing will improve health, promote gender equality and support economic growth [Internet]. London: APPG; 2016 [cited 2020 July 20]. Available from: http://www.appg-globalhealth.org.uk 6. World Health Organization (WHO). Fifty-eighth World Health Assembly [Internet]. Geneva: WHO; 2005. Chapter WHA58.34, Ministerial summit on health research; [cited 2020 July 20]; [pp. 126-8]. Available from: http://apps.who.int/gb/ebwha/pdf_files/WHA58-REC1/A58_2005_REC1-en.pdf

\section{Como citar este artigo:}

Pereira EGA. O valor socioeconómico da enfermagem no contexto de pandemia pela Covid19 - cenário em Portugal. Revista de Enfermagem do Centro Oeste Mineiro. 2020;10:e4142. [Access ]; Available in: DOI: http://dx.doi.org/10.19175/recom.v10i0.4142 